\title{
The 4.2 ka BP Event in northeastern China: a geospatial perspective
}

\author{
Louis A. Scuderi ${ }^{1}$, Xiaoping Yang ${ }^{2}$, Samantha E. Ascoli ${ }^{1}$, and Hongwei $\mathbf{L i}^{2}$ \\ ${ }^{1}$ Department of Earth and Planetary Sciences, University of New Mexico, Albuquerque, NM, USA \\ ${ }^{2}$ School of Earth Sciences, Zhejiang University, Hangzhou, Zhejiang Province, China
}

Correspondence: Louis A. Scuderi (tree@unm.edu)

Received: 11 August 2018 - Discussion started: 12 October 2018

Accepted: 28 December 2018 - Published: 21 February 2019

\begin{abstract}
The Hunshandake Sandy Lands of northeastern China, currently a semiarid lightly vegetated region, were characterized by perennial lakes and forest stands in the early and middle Holocene. Well-developed dark grassland-type paleosols (mollisols) at the southern edge of the Hunshandake - OSL (optically stimulated luminescence)-dated to between $6.93 \pm 0.61$ and $4.27 \pm 0.38 \mathrm{ka}$ along with lacustrine sands at higher elevations that date to between $5.7 \pm 0.3$ and $5.2 \pm 0.2 \mathrm{ka}$ - and thick gray lacustrine sediments suggest a wetter climate. Between 4.2 and $3.8 \mathrm{ka}$, the region experienced extreme drying that was exacerbated by lake overflow drainage and sapping that depleted the groundwater table. The region supported a robust population, the Hongshan Culture, but was depopulated post $4.2 \mathrm{ka}$ with migration likely to the Yellow River Valley where the Hongshan introduced their characteristic cultural elements to early Chinese civilization. Evidence for extreme and sudden environmental change in northeastern China, at and following the 4.2 ka BP Event and like that we document in the Hunshandake, is widespread. However, no comprehensive overview of this climatic episode exists. Here, we discuss the relevant events in northeastern China and capture them in a spatially explicit Geographic Information Systems database that can be used to analyze the timing and spatial pattern of climate and environmental change associated with the $4.2 \mathrm{ka} \mathrm{BP}$ Event. This approach could serve as a prototype for a global 4.2 ka BP Event database.
\end{abstract}

\section{Introduction}

The Hunshandake Sandy Lands of northeastern China (Fig. 1) are currently characterized by grasslands that overlie semi-stabilized aeolian deposits in its southern and eastern regions and by aeolian sand sheets and dunes in its western region. The current desert-like landscape was covered by lakes and forests during the early and middle Holocene (Jiang et al., 2006; Yang and Scuderi, 2010; Yang et al., 2015; Xiao et al., 2018) with bioclimatic regimes reflecting significantly wetter conditions associated with an intensified monsoon precipitation up to $50 \%$ higher than current conditions (Yang et al., 2011, 2013). The region supported a significant population that lived in small communities and relied on fishing and hunting (Liu and Feng, 2012; Wagner et al., 2013).

A sudden shift from wet to dry conditions in the Hunshandake and for most of northeastern China occurs at $\sim 4.2 \mathrm{ka}$ (Yang et al., 2015). While the primary driver appears to be linked to global-scale change occurring at that time, in the Hunshandake it was exacerbated by rapid groundwater drawdown resulting from drainage capture. This combined climatic and hydrologic reorganization led to a rapid loss of surface water and a shift from green to sandy conditions over a few hundred years. This environmental shift produced regional depopulation with a significant abandonment of sites across the region lasting until $\sim 3.6 \mathrm{ka}$ (Liu and Feng, 2012; Wagner et al., 2013; Yang et al., 2015).

The change in environmental conditions in the Hunshandake is not unique within China. Evidence for a putative 4.2 ka BP Event appears at sites across China's deserts (Feng et al., 2006) and in many records from northeast China (Hong et al., 2001; Liu et al., 2002, 2010; Xiao et al., 2018). Globally, the underlying cause for this event is controversial 


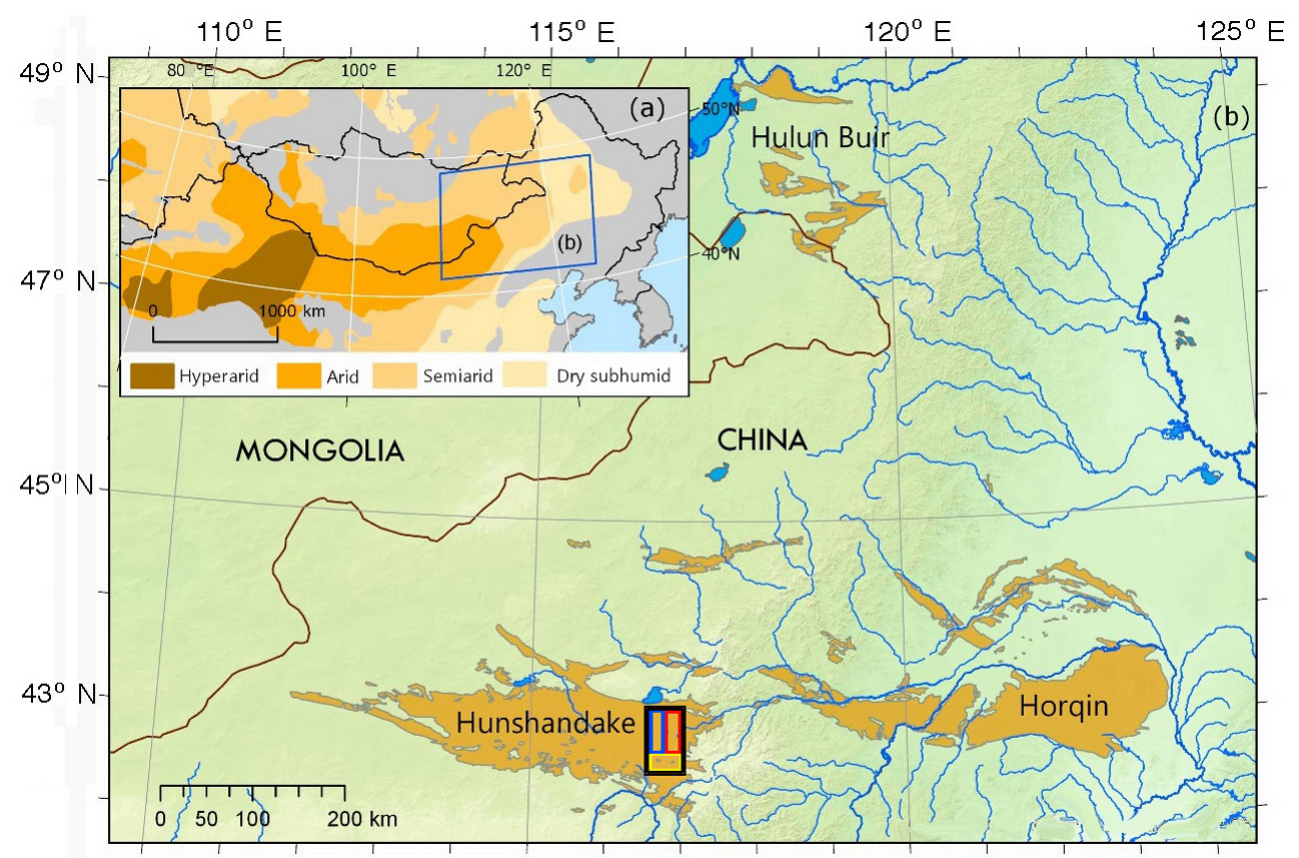

Figure 1. Sandy Lands of northeastern China. (a) Distribution of deserts across China by climate type. (b) Sandy land distribution. Boxed area in Hunshandake Sandy Lands is study area reported in this study. Regions: south - yellow; west - blue; east - red.

(Weiss and Bradley, 2010; Weiss, 2016, 2017). Part of the problem in deciphering this event includes a lack of understanding of the drivers of the global climate system at ca. $4.2 \mathrm{ka}$, the spatial and temporal coherence of this event, and the sensitivity of different ecologic, hydrologic, and geomorphic systems to forcings of this magnitude.

In this paper we review the environmental change that took place in the Hunshandake bracketing the $4.2 \mathrm{ka} \mathrm{BP}$ Event and place it in context relative to other records from northeastern China. To better understand the event's temporal and spatial characteristics, we analyzed the existing literature, developed a geospatially explicit Geographic Information System database from this literature, and used it to map evidence for the $4.2 \mathrm{ka}$ BP Event. We conclude with a discussion of how such a data structure and analysis approach might be used to better understand the $4.2 \mathrm{ka} \mathrm{BP}$ Event globally, and we provide the dataset for evaluation and analysis as an online supplement.

\subsection{Study area}

China is characterized by a broad swath of deserts that extend between $38^{\circ}$ and $46^{\circ} \mathrm{N}$. This desert belt is roughly divided at the Helan Mountains into a western portion of "true" hyperarid and arid deserts and a slightly wetter eastern portion consisting of lightly vegetated and stabilized semiarid to dry subhumid "Sandy Lands". The Hunshandake Sandy Lands (Fig. 1; elevation 1100-1400 m), along with the Horqin and Hulun Buir, are found on the eastern edge of this desert belt in northeastern China. Ecologically the Hunshandake is a semiarid grassland ecosystem underlain primarily by aeolian sandy soils. Monthly temperatures range from $-18.3^{\circ} \mathrm{C}$ in January to $+18.5^{\circ} \mathrm{C}$ in July with annual precipitation across the region between 150 and $450 \mathrm{~mm}$ and falling primarily during the summer months.

\subsection{Holocene climatic history}

The Hunshandake Sandy Lands can be subdivided into southern, western, and eastern units. The southern part of the region is characterized by low hills vegetated by a thin cover of grasses and shrubs and has an absence of standing water. The western part of the region is primarily low hills with a grassland cover and standing lakes while the eastern portion is grassland and low rolling vegetated dunes with dry lake beds. While all three are currently semiarid and lightly vegetated, they differed significantly in their response to climate change at $4.2 \mathrm{ka}$.

The Holocene environment of this area is discussed in detail in Yang et al. (2015). We briefly summarize the findings below. Figure 2 illustrates two well-developed dark grassland-type paleosols (mollisols) at the southern edge of the Hunshandake that are identifiable and can be traced across the entire region. Lacustrine sands underlying these paleosols indicate an earlier lake/wetland environment. The lower paleosol is OSL-dated to between $6.93 \pm 0.61$ and $4.27 \pm 0.38 \mathrm{kaBP}$ and suggests a period of wetter climate that rapidly transitioned to dry conditions at ca. $4.2 \mathrm{ka}$. The 
(a)

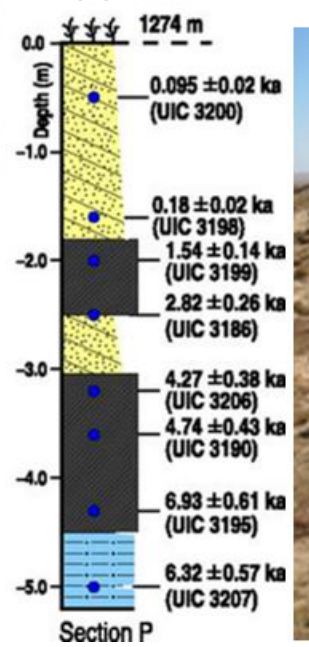

(b)

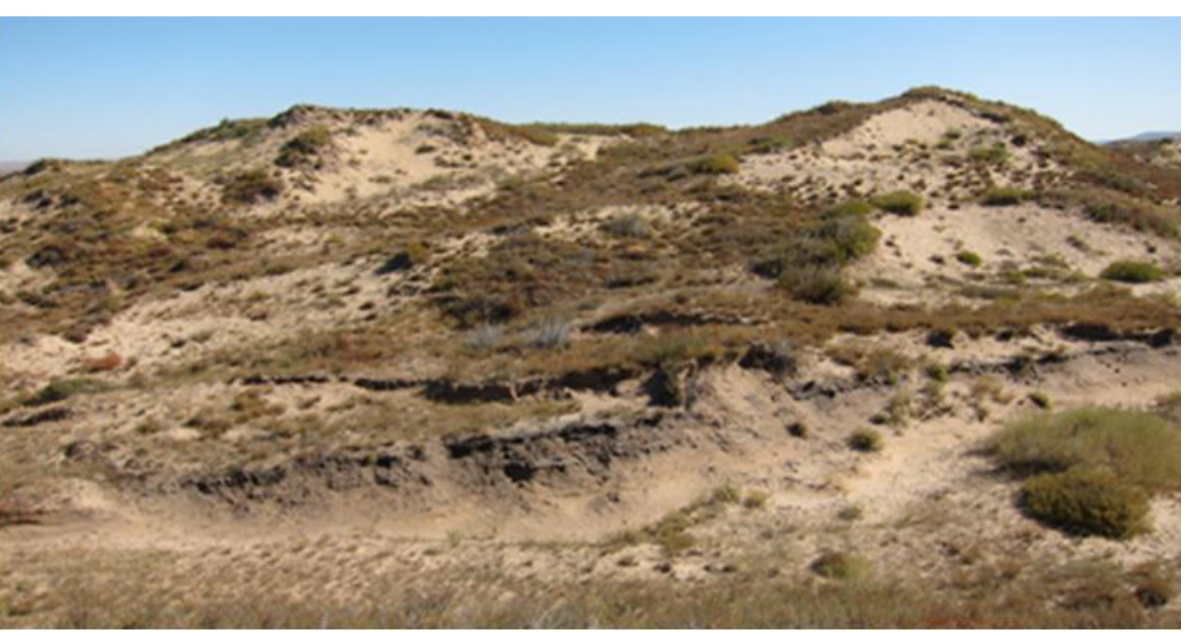

Figure 2. Southern Hunshandake. (a) Section P from Yang et al. (2015) showing paleosols and sandy units which overlie an earlier lacustrine unit. (b) Sampled exposure showing the two paleosols.

southern part of the Hunshandake, as indicated by a second paleosol dated to between $2.82 \pm 0.26$ and $1.54 \pm 0.14 \mathrm{ka} \mathrm{BP}$, returned to green conditions again at ca. $2.8 \mathrm{ka} \mathrm{BP}$ and maintained this state for $\sim 1500$ years. Dune sediments reflecting an active aeolian environment have dominated since $\sim$ $1.3 \mathrm{ka}$.

The eastern Hunshandake (Figs. 3 and 4), while exhibiting evidence of the $4.2 \mathrm{kaBP}$ Event in terms of paleosols and abandoned shoreline features, does not exhibit a return to grassland conditions between $\sim 2.8$ and $1.5 \mathrm{ka} \mathrm{BP}$ with sandy conditions persisting since the onset of the $4.2 \mathrm{ka} \mathrm{BP}$ Event. As Yang et al. (2015) found, this difference was associated with the redirection of drainage from its northerly flow towards Dali Lake at ca. $4.5 \mathrm{ka}$ by the capture of surface water and the groundwater table by the Xilamulun River. This may be reflected in the longest period of low stands of both Dali (Xiao et al., 2008, 2018) and Dai Hai (Xiao et al., 2004, 2006) lakes between ca. 4.5 and $3.8 \mathrm{ka}$. The eastward drainage shift resulting from this capture, coupled with channel entrenchment via groundwater sapping resulted in longterm drying of the eastern Hunshandake, likely moisture enhancement of the downstream Horqin Sandy Land, and the abandonment the region by the Hongshan culture (Peterson et al., 2010) ca. 4.5-4.2 ka. Recent mapping has revealed a lack of artifacts in the eastern Hunshandake between 4.3 and $3.5 \mathrm{ka}$ (Liu and Feng, 2012; Wagner et al., 2013). In the eastern Hunshandake Sandy Lands, Hongshan artifacts are found primarily within and below the $4.2 \mathrm{ka}$ paleosols and shorelines while Bronze Age artifacts (Fig. 3b), which appear in the region ca. 3.6 ka (Wagner et al., 2013), lie on or above the $4.2 \mathrm{ka}$ paleosol.

\section{Results}

\subsection{Deriving and understanding the regional signal in northeast China}

The 4.2 ka BP Event continues to puzzle scientists with respect to its spatial extent, triggering mechanisms, and regional to global characteristics. As shown above, the difference in response between sites within the Hunshandake separated by less than $100 \mathrm{~km}$ illustrates some of the complications that can arise from point source reconstructions. In northeastern China records are dominated by evidence from sediments and pollen from lacustrine and aeolian environments. At times these records present conflicting views of the 4.2 ka BP Event. In the following we discuss some of the issues with interpreting regional mappings of this diverse set of records and provide an approach to reconstructing the regional signal of this event.

Parmesan and Yohe (2003) note that detection of a climate change signal is a search for spatially and temporally coherent sign-switching patterns. This search is complicated by the time-transgressive and rate response differing nature of complex interacting systems as well as possible spatially diffusive responses across a landscape. While records from individual sites provide snapshots of what occurred at a given locality, interpretation is often complicated by significant uncertainty in dating and possible regionalization of the observed signal.

\subsection{Database creation}

Placing the Hunshandake record in context relative to northeast China, and within the larger global context, requires the assembly of records from many diverse sources into a sin- 

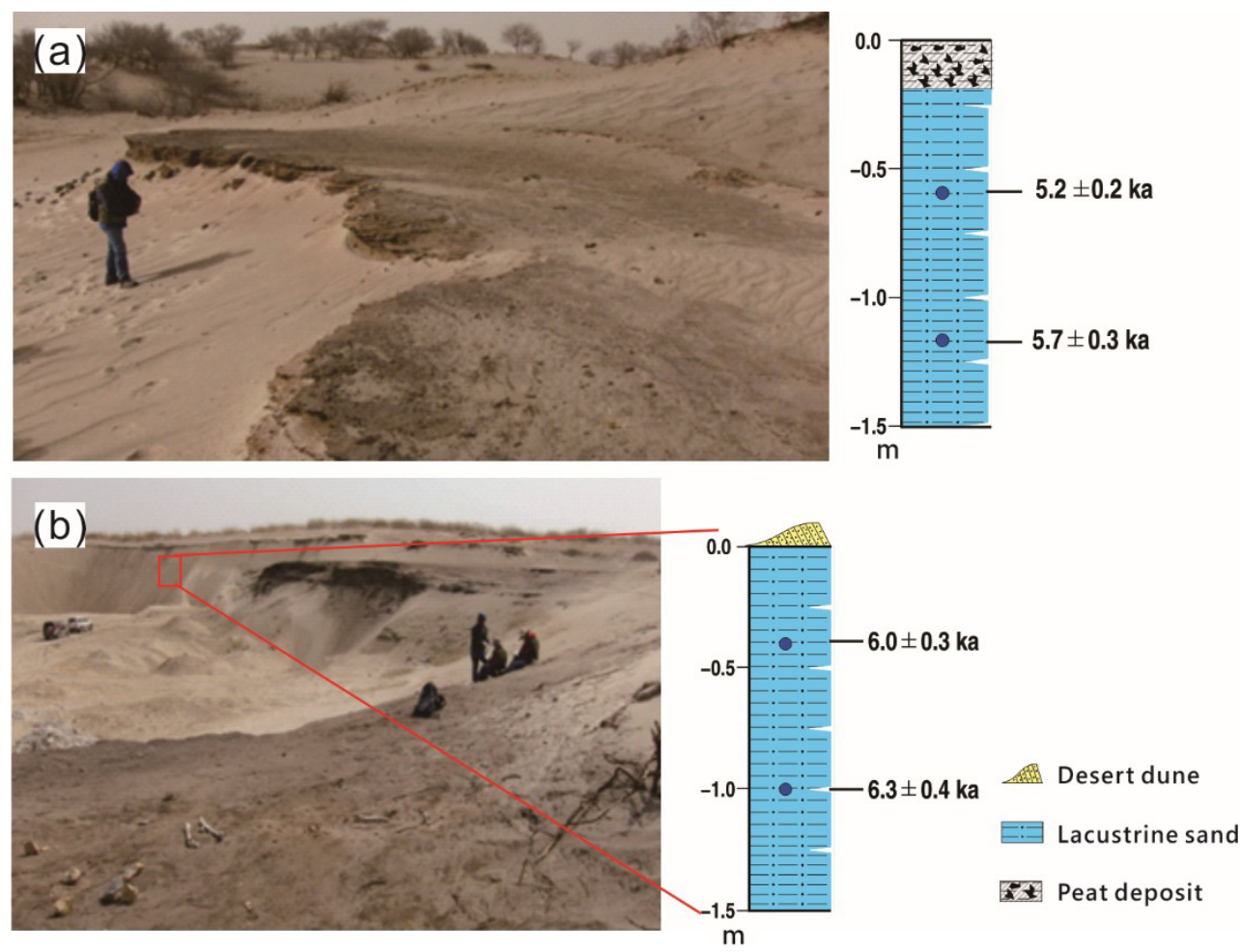

Figure 3. Eastern Hunshandake lacustrine deposits capped by paleosols. (a) Eastern Hunshandake paleosol/lakeshore (Section I from Yang et al., 2015). (b) Bronze age burial (lower left) on the surface of the lake shore exposed by deflation (Section E from Yang et al., 2015).
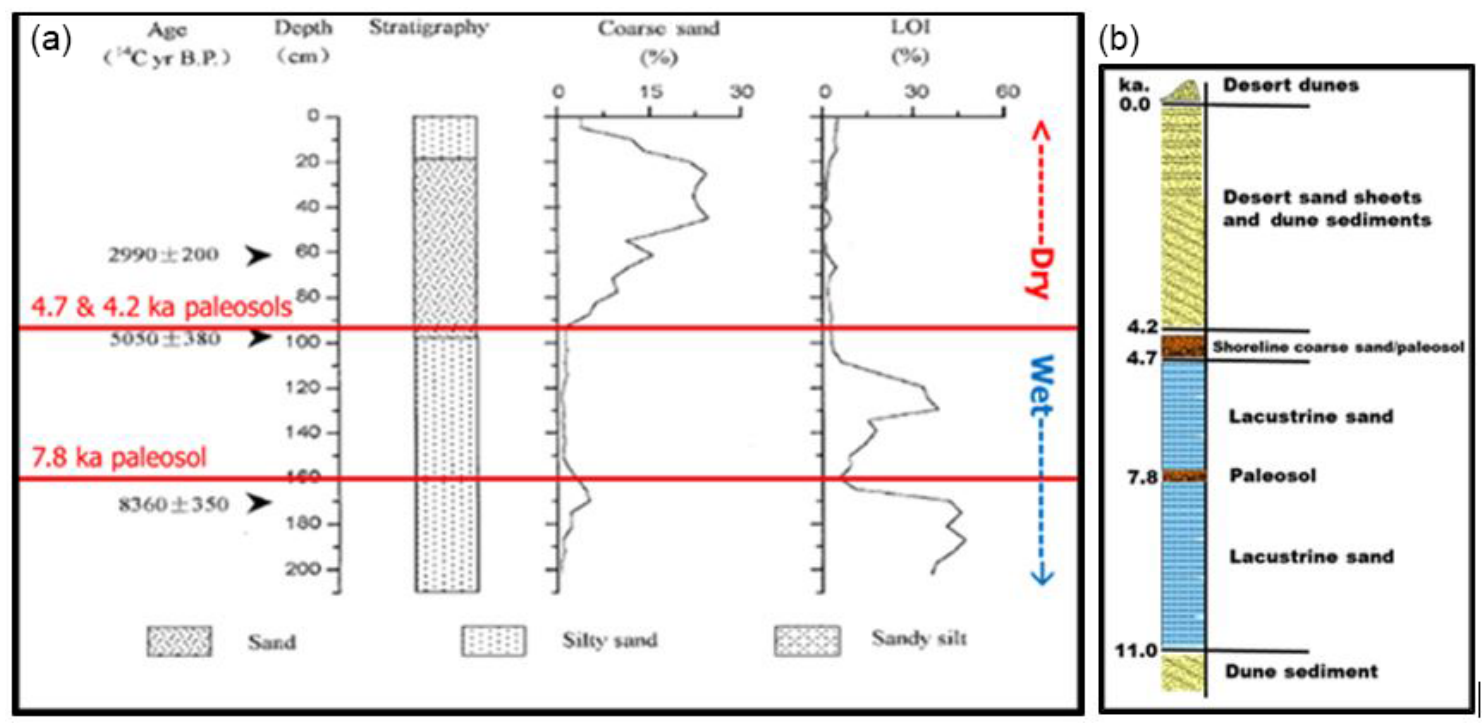

Figure 4. (a) Core records from Xiaoniuchang (after Liu et al., 2002). (b) General Holocene reconstruction of eastern Hunshandake Sandy Lands (Yang et al., 2015). The coarse sand fraction increases significantly following the $4.2 \mathrm{ka}$ BP Event with sediments dominated by desert sand sheets and dunes.

gle data repository/database with well-defined and consistent terminology. Without such efforts, such databases are simply collections of facts and observations rather than knowledge generation tools. To "redefine" the problem and to min- imize database problems associated with definitional confusion (semantic) and locational (spatial) and dating (temporal) uncertainty, we approached the $4.2 \mathrm{ka}$ BP Event from a different perspective, namely by letting the body of existing 


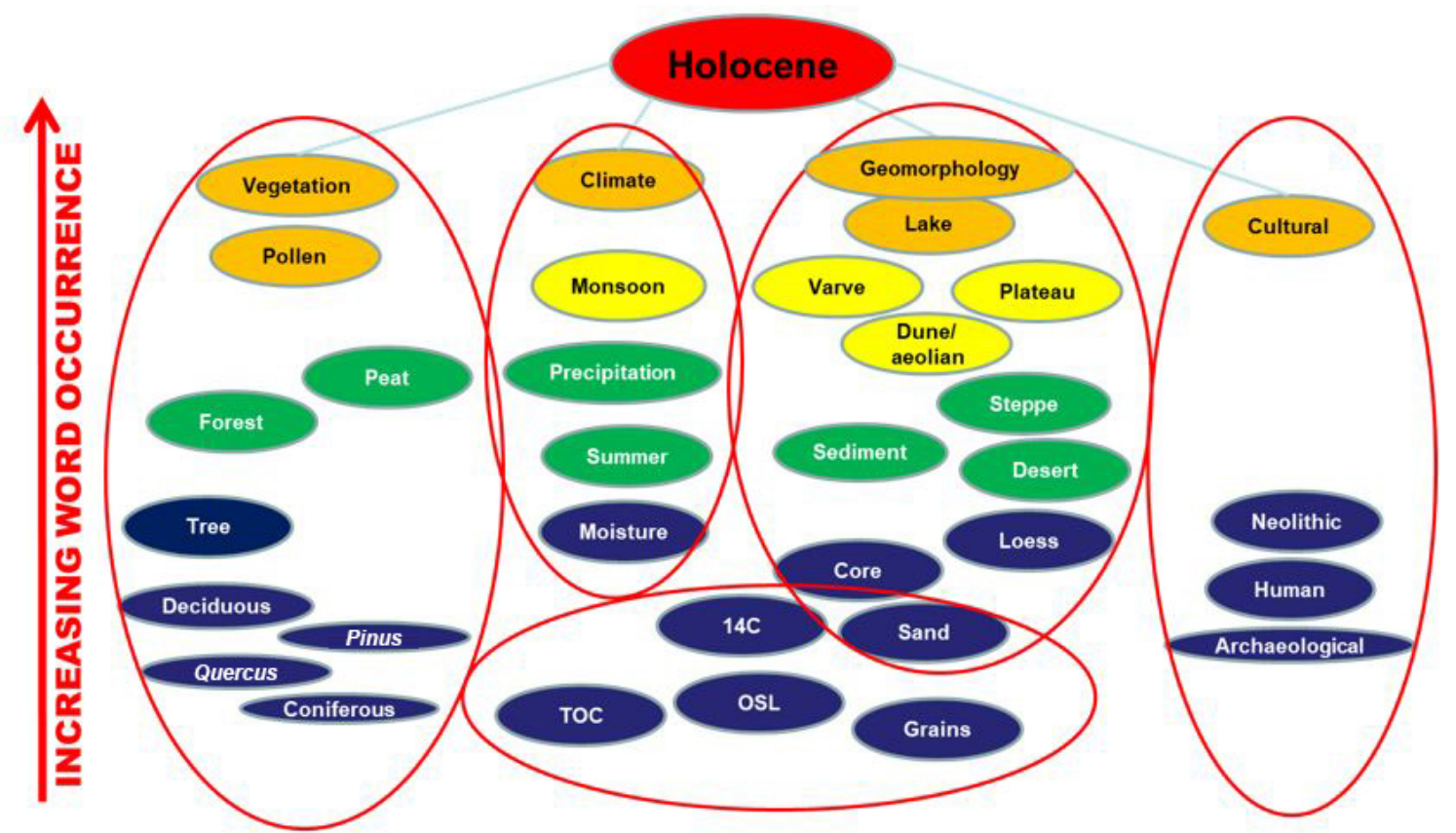

Figure 5. Topic map. Word extraction organized by number of words and topics (ovals: red - highest; blue - lowest; increasing number of occurrences from bottom to top) and by four major topic groups (left - vegetation; middle left - climate; middle right - geomorphic/sedimentologic type; right - cultural). Lower center - analysis type. TOC: table of contents.

data define the parameters and structure of the information space we were exploring. To do so we utilized conceptual spaces for defining the informational architecture of our reconstruction of the $4.2 \mathrm{kaBP}$ Event in northeast China. We note that such information context extraction may be useful in the identification of similar and differing responses between regions and understanding how these expressions of the 4.2 ka BP Event may have varied spatially and temporally.

We collected and analyzed 60 peer-reviewed articles (listed 1-60 in the online digital archive) pertaining to middle to late Holocene climate and environmental conditions in northeast China. Duplicate records reflecting multiple papers dealing with the same site were eliminated unless we believed that the given paper introduced a new analysis/interpretation for a given site. This analysis included text, figures, and tables. Using a web-enabled open-access semantic parser (Word Count Tool: High Star App, 2017: https://wordcounttools.com/, last access: 28 December 2018) we extracted $\sim 430000$ words (excluding simple words "a", "it", "the", etc. - as well as dates). While the word counter provides extensive information about word use and structure, in our analysis we used only raw word count statistics. From this output we identified the 30 most used words from each article ( 224 critical words distributed across the 60 articles). These critical words appear 28289 times $(\sim 6.5 \%)$ in the articles analyzed.
We organized the words by similarity and number of occurrences (Fig. 5) and derived database tables (Fig. 6) with explicit geocoding that were input into ARCInfo (ESRI, 2018) for geospatial analysis. We also included paleoclimate reconstructions of mid-Holocene (6.0 ka BP) climatic parameters derived from the Coupled Model Intercomparison Project 5 (CMIP5) data. These downscaled data (30 s resolution) were calibrated (bias corrected) using WorldClim 1.4 (Hijmans et al., 2005) as a baseline for "current" climate and were used as a reference for conditions prior to $4.2 \mathrm{ka}$. Using ARCGIS we clipped the output for each of these models to our study area (Fig. 1) and included them in our database. This includes layers for monthly average minimum temperature, monthly average maximum temperature, monthly total precipitation, and 19 bioclimatic variables derived from WorldClim data (source: http://worldclim.org/bioclim, last access: 24 January 2019). An example showing modeled $6.0 \mathrm{ka}$ BP annual precipitation from the Beijing Climate Center Climate System Model (BCC-CSM1.1) (Fig. 7) is useful for illustrating the wide range of a single climatic variable across our northeast China study area $\left(\sim 1500 \mathrm{~km}^{2}\right)$ and the potential difficulties arising from using individual site (point) data in assessing the impact of the $4.2 \mathrm{ka}$ BP Event.

Finally, following the lead of Parmesan and Yohe (2003), we identified the $4.2 \mathrm{ka}$ state change (yes, no) and rate and direction of change (rates: +2 to -2 , with 0 being no change and positive or negative indicating an increase or decrease in the measured variable) from the text and figures in each 


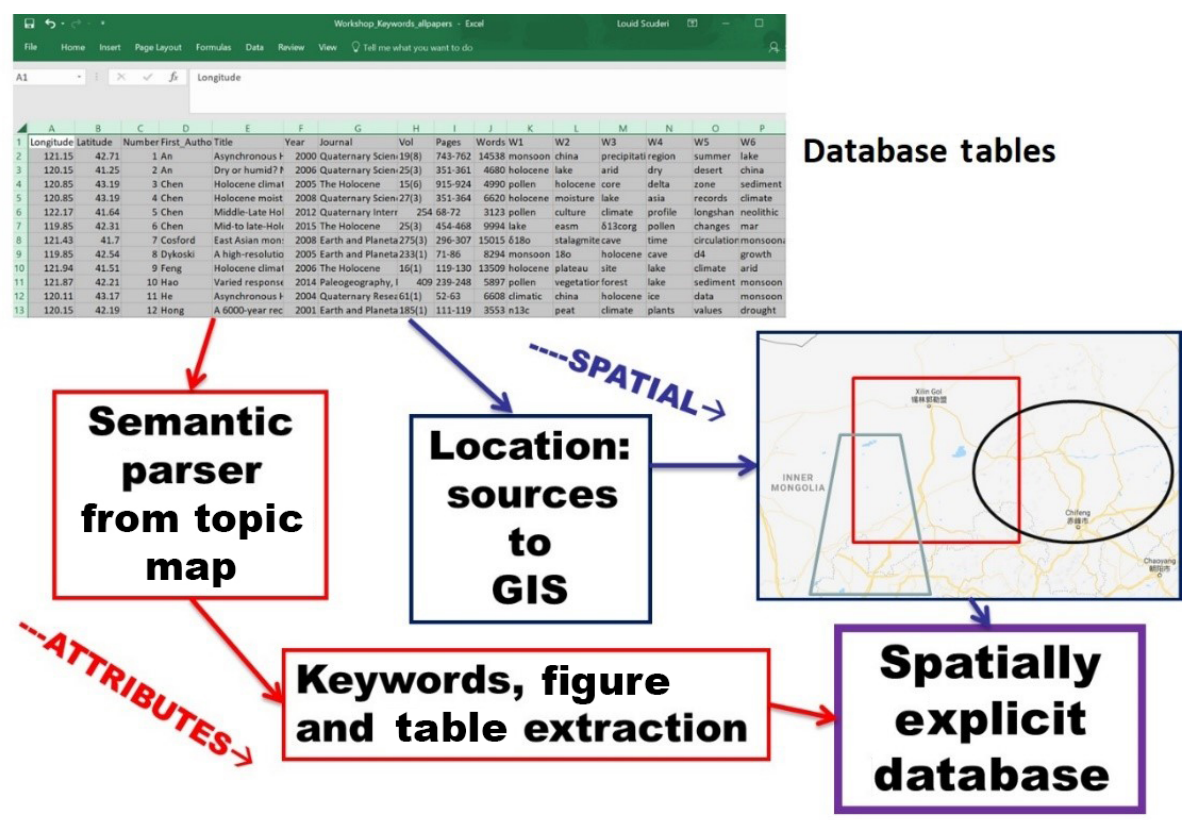

Figure 6. Overview of the processing schema for database production. Each article was geocoded and combined with tables derived from keywords to produce the final GIS-compatible spatially explicit database for analysis.

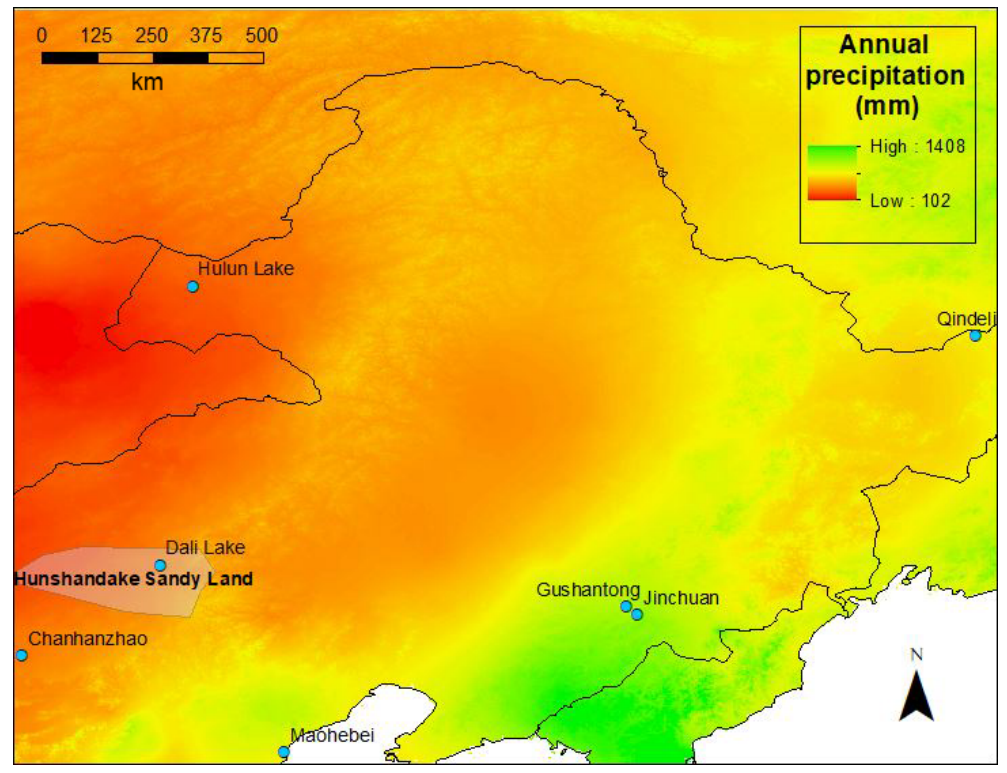

Figure 7. Modeled annual precipitation (mm) for 6.0 ka BP (Hijmans et al. 2005) from the Beijing Climate Center Climate System Model (Version 1.1). Seven sites derived from An et al. (2000) are shown (green dots) to illustrate the incomplete spatial distribution of records within individual research records across the region.

article and linked them in the database to the specific topic group they were derived from. This allows analysis and mapping of the distribution, intensity and directionality of $4.2 \mathrm{ka}$ marker events, or lack thereof, of the different types of evidence available.

\section{Analysis}

An example of regional results for change at $4.2 \mathrm{ka}$ (presence or absence of $4.2 \mathrm{kaBP}$ Event) is illustrated in Fig. 8 . It is clear from the distribution of points that the signature of a $4.2 \mathrm{kaBP}$ Event is strong but not universal at all sites, with $\sim 23 \%$ (18/77) reported showing inconclusive or no 


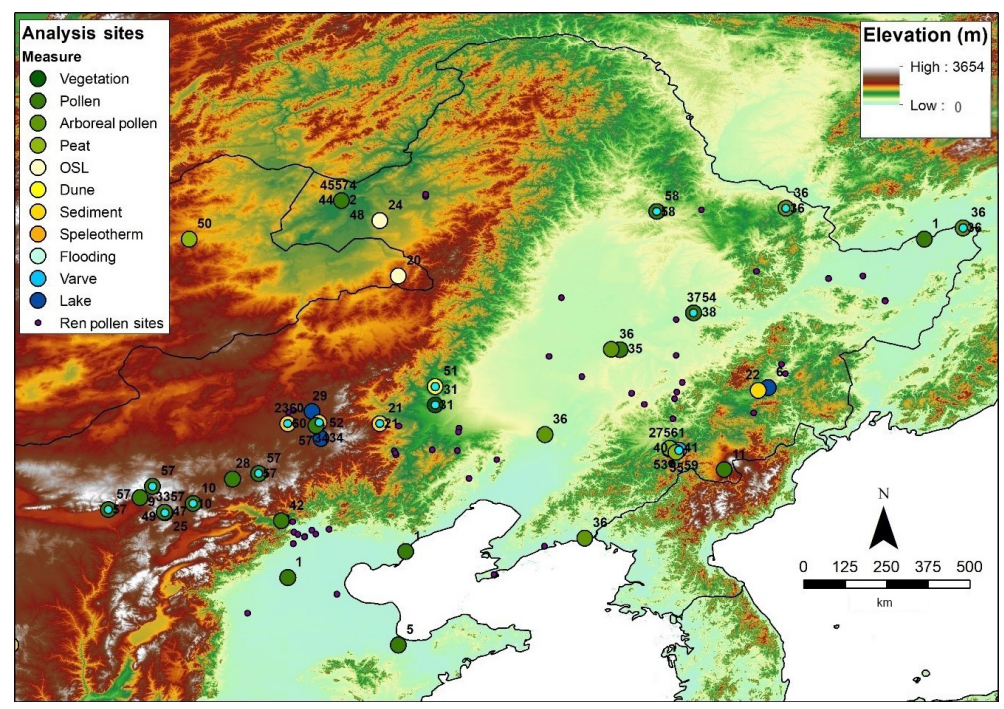

Figure 8. 4.2 ka BP Event analysis sites by type of evidenced measured (numbered site information can be found in the online data archive). Note the lack of sites in the northern portion of the region (Heilongjiang Province and NE inner Mongolia). Light blue dots within individual measures indicate sites with no change across the 4.2 ka BP Event. Small purple dots are pollen sites from Ren and Zhang (1998) derived from published work and unpublished dissertations. While not all sites cover the $4.2 \mathrm{ka}$ BP Event, we include the Ren and Zhang data to show the distribution of late Holocene paleoclimatic reconstruction work in NE China.

evidence of the $4.2 \mathrm{kaBP}$ Event. Spatial analysis of the distribution of these records reveals an interesting pattern with both coastal sites and sites over $750 \mathrm{~km}$ from the coast showing consistent evidence for change at $4.2 \mathrm{ka}$. However, an intermediate band of higher-elevation sites between 300 and $500 \mathrm{~km}$ from the coast that are primarily derived from measures of vegetation type or abundance show inconsistent evidence for the $4.2 \mathrm{kaBP}$ Event. Determining whether this is the result of interpretation errors, lack of sensitivity and/or temporal resolution, or the actual absence of environmental markers for the event will require additional research.

While there appears to be a significant level of coherence that suggests a relatively strong $4.2 \mathrm{ka}$ signature across northeast China there are examples of local results that are inconsistent with this generalization. As we report in this paper, and in Yang et al. (2015), within the Hunshandake sites separated by as little as $100 \mathrm{~km}$ (Haoluku $42.95^{\circ} \mathrm{N}, 116.76^{\circ} \mathrm{E}$; Xiaoniuchang $42.62^{\circ} \mathrm{N}, 116.82^{\circ} \mathrm{E}$ ) exhibit signals that differ significantly. Liu et al. (2002) suggested, that these differences might be due to a combination of elevation (Xiaoniuchang 1460 m; Haoluku 1295 m), local conditions (Xiaoniuchang at the edge of a lake and Haoluku at its center), and transport of sediment due to changing environmental conditions (Xiaoniuchang dried up earlier than Haoluku which was still experiencing inflow of coarse sediments). Dating precision and uncertainty, as well as variability in local groundwater conditions and local and regional differences in topographic relief, may also result in apparent differences between local sequences both within the Hunshandake and in other localities that we document. While we currently do not have the ability to recognize different parts of the $4.2 \mathrm{ka} \mathrm{BP}$ Event in northeast China, as has been done for the central and western Mediterranean region (Magny et al., 2009), it is clear from the records we analyzed that the event is likely to have had multiple phases in northeast China.

\section{Conclusions}

The lack of integration of data into a scientifically credible, globally assembled information platform with consistent terminology and definitions to guide scientific inquiry hinders the understanding of the $4.2 \mathrm{kaBP}$ Event. The creation of such an information platform can allow researchers to ask questions about the spatial distribution and environmental indicators that characterize this event. Such a platform can expand the range of research questions that can be tackled, encourage innovative and collaborative research, allow data sharing and comparison of results, and facilitate the development of innovative analytic tools. As Yin (2005) noted, the end goal of this type of research "is a data structure that sits firmly upon the deep-seated, some might say, hard-wired, natural structures of the information architecture".

Using this database approach, we showed the presence of a strong and coherent signal for the $4.2 \mathrm{ka} \mathrm{BP}$ Event in northeastern China, albeit with local and regional variation that complicates interpretation. Much of this complication may be the result of the use of different standards, differing interpretations of the data, data gaps, and differential spatial and temporal responses of indicators analyzed and reported. We note three important issues that broaden any palaeoclimatic 
estimate and introduce additional uncertainty to this analysis: (1) temporal resolution - different resolution between different dating techniques; (2) localization versus regionalization - some measures are "local" while others integrate "regional" conditions (for instance sediment in a small isolated lake basin versus a lake that is the terminal sink of a large area, respectively); (3) lagged response - the possibility of differential and lagged responses for different measures of the same event.

While much work remains, our prototype database approach, guided by semantic analysis of the literature and georeferencing of existing data sources, can serve as a guide to the assembly of a larger-scale global $4.2 \mathrm{ka}$ database that should allow a better understanding of this climatic event. The reader is encouraged to use the datasets found in the 4.2 ka data repository to both explore the 4.2 ka relationships in northeast China and to possibly guide the development of similar databases for other regions.

Data availability. All data used in this project can be found in the University of New Mexico's digital repository. The persistent and secured URL for this site is https://digitalrepository.unm.edu/ paleoclimate/ (Scuderi et al., 2019; last access: 12 February 2019). The site is named 4.2K PALEOCLIMATE PROJECT.

The data are part of the $4.2 \mathrm{~K}$ Paleoclimate Project Collections, which contain subdirectories for both the paleoclimate datasets supporting the project and research publications derived from the project.

This is considered to be an active research database and will be updated on a regular basis as new data, analysis, and publications become available.

Author contributions. LAS and SEA developed the Geographic Information System database, and LAS performed the model runs. LAS and HL prepared graphics. LAS prepared the paper with contributions from all coauthors.

Competing interests. The authors declare that they have no conflict of interest.

Special issue statement. This article is part of the special issue "The $4.2 \mathrm{ka}$ BP climatic event". It is a result of "The $4.2 \mathrm{ka} \mathrm{BP}$ Event: An International Workshop", Pisa, Italy, 10-12 January 2018.

Acknowledgements. The authors would like to thank the 4.2 ka BP Event conference organizers for providing a venue for this work. Louis A. Scuderi and Samantha E. Ascoli would like to thank the University of New Mexico for travel and computing support. Xiaoping Yang and Hongwei Li would like to thank the School of Earth Sciences, Zhejiang University, Hangzhou, Zhejiang Province, P. R. China for continued support. Samantha E. Ascoli would like to thank the Leonard Foundation for research support. We also thank two anonymous reviewers for excellent comments and suggestions, which improved the final paper.

Edited by: Giovanni Zanchetta

Reviewed by: two anonymous referees

\section{References}

An, Z., Porter, S. C., Kutzbach, J. E., Xihao, W., Suming, W., Xiaodong, L., Xiaoqiang, L., and Weijian, Z.: Asynchronous Holocene optimum of the East Asian monsoon, Quaternary Sci. Rev., 19, 743-762, 2000.

ESRI: ARCInfo 10.5.1, Environmental Systems Research Institute, Redlands, CA, USA, 2018.

Feng, Z. D., An, C. B., and Wang, H. B.: Holocene climatic and environmental changes in the arid and semi-arid areas of China: a review, Holocene, 16, 119-130, 2006.

Hijmans, R. J., Cameron, S. E., Parra, J. L., Jones, P. G., and Jarvis, A.: Very high resolution interpolated climate surfaces for global land areas, Int. J. Climatol., 25, 1965-1978, 2005.

Hong, Y. T., Wang, Z. G., Jiang, H. B., Lin, Q. H., Hong, B., Zhu, Y. X., Wang, Y., Xu, L. S., Leng, X. T., and Li, H. D.: A 6000year record of changes in drought and precipitation in northeastern China based on a $\delta^{13} \mathrm{C}$ time series from peat cellulose, Earth Planet. Sc. Lett., 185, 111-119, 2001.

Jiang, W., Guo, Z., Sun, X., Wu, H., Chu, G., Yuan, B., Hatté, C., and Guiot, J.: Reconstruction of climate and vegetation changes of Lake Bayanchagan (Inner Mongolia): Holocene variability of the East Asian monsoon, Quaternary Res., 65, 411-420, 2006.

Liu, F. and Feng, Z.: A dramatic climatic transition at 4000 cal. yr BP and its cultural responses in Chinese cultural domains, Holocene, 22, 1181-1197, 2012.

Liu, H., Xu, L., and Cui, H.: Holocene history of desertification along the woodland-steppe border in northern China, Quaternary Res., 57, 259-270, 2002.

Liu, H., Yin, Y., Zhu, J., Zhao, F., and Wang, H.: How did the forest respond to Holocene climate drying at the forest-steppe ecotone in northern China?, Quatern. Int., 227, 46-52, 2010.

Magny, M., Vannière, B., Zanchetta, G., Fouache, E., Touchais, G., Petrika, L., Coussot, C., Walter-Simonnet, A. V., and Arnaud, F.: Possible complexity of the climatic event around 43003800 cal. BP in the central and western Mediterranean, Holocene, 19, 823-833, 2009.

Parmesan, C. and Yohe, G.: A globally coherent fingerprint of climate change impacts across natural systems, Nature, 421, 37-42, 2003.

Peterson, C. E., Lu, X., Drennan, R. D., and Zhu, D.: Hongshan chiefly communities in Neolithic northeastern China, P. Natl. Acad. Sci. USA, 107, 5756-5761, 2010.

Ren, G. and Zhang, L.: A preliminary mapped summary of Holocene pollen data for Northeast China, Quaternary Sci. Rev., 17, 669-688, 1998.

Scuderi, L. A., Yang, X., Ascoli, S. E., and Li, H.: Data to "The 4.2 ka BP Event in northeastern China: a geospatial perspective", available at: https://digitalrepository.unm.edu/paleoclimate/, last access: 12 February 2019.

Wagner, M., Tarasov, P., Hosner, D., Fleck, A., Ehrich, R., Chen, X., and Leipe, C.: Mapping of the spatial and temporal distribution 
of archaeological sites of northern China during the Neolithic and Bronze Age, Quatern. Int., 290, 344-357, 2013.

Weiss, H.: Global megadrought, societal collapse and resilience at 4.2-3.9 ka BP across the Mediterranean and west Asia, PAGES Mag., 24, 62-63, 2016.

Weiss, H.: Megadrought and collapse: from early agriculture to Angkor, Oxford University Press, Oxford, UK, 2017.

Weiss, H. and Bradley, R. S.: What drives societal collapse?, Science, 291, 609-610, 2010.

Xiao, J., Xu, Q., Nakamura, T., Yang, X., Liang, W., and Inouchi, Y.: Holocene vegetation variation in the Daihai Lake region of north-central China: a direct indication of the Asian monsoon climatic history, Quaternary Sci. Rev., 23, 1669-1679, 2004.

Xiao, J. L., Wu, J. T., Si, B., Liang, W. D., Nakamura, T., Liu, B. L., and Inouchi, Y.: Holocene climate changes in the monsoon/arid transition reflected by carbon concentration in Daihai Lake of Inner Mongolia, Holocene 16, 551-560, 2006.

Xiao, J. L., Si, B., Zhai, D. Y., Itoh, S., and Lomtatidze, Z.: Hydrology of Dali Lake in central-eastern Inner Mongolia and Holocene East Asian monsoon variability, J. Paleolimnol., 40, 519-528, 2008.

Xiao, J., Zhang, S., Fan, J., Wen, R., Zhai, D., Tian, Z., and Jiang, D.: The 4.2 ka BP event: multi-proxy records from a closed lake in the northern margin of the East Asian summer monsoon, Clim. Past, 14, 1417-1425, https://doi.org/10.5194/cp-14-1417-2018, 2018.
Yang, X. and Scuderi, L. A.: Hydrological and climatic changes in deserts of China since the late Pleistocene, Quaternary Res., 73, $1-9,2010$.

Yang, X., Scuderi, L., Paillou, P., Liu, Z., Li, H., and Ren, X.: Quaternary environmental changes in the drylands of China - a critical review, Quaternary Sci. Rev., 30, 3219-3233, 2011.

Yang, X., Wang, X., Liu, Z., Li, H., Ren, X., Zhang, D., Ma, Z., Rioual, P., Jin, X., and Scuderi, L.: Initiation and variation of the dune fields in semi-arid China - with a special reference to the Hunshandake Sandy Land, Inner Mongolia, Quaternary Sci. Rev., 78, 369-380, 2013.

Yang, X., Scuderi, L. A., Wang, X., Scuderi, L. J., Zhang, D., Li, H., Forman, S., Xu, Q., Wang, R., Huang, W., and Yang, S.: Groundwater sapping as the cause of irreversible desertification of Hunshandake Sandy Lands, Inner Mongolia, northern China, P. Natl. Acad. Sci. USA, 112, 702-706, 2015.

Yin, M.: Preface to Hierarchy Papers, in: International Conference on Topic Map Research and Applications, edited by: Park, J. and Cheyer, A., Springer, Berlin, Heidelberg, Germany, 145159, 2005. 